\title{
PENGEMBANGAN SISTEM DATABASE BERBASIS TRI DARMA PERGURUAN TINGGI PADA PROGRAM STUDI PENDIDIKAN EKONOMI
}

\author{
Tri Nugroho Budi Santoso \\ Program Studi Pendidikan Ekonomi, Universitas Kristen Satya Wacana \\ Jl. Diponegoro 52-60 Salatiga - Indonesia \\ E-mail: tri.budi.santoso@uksw.edu
}

\begin{abstract}
Document management is important for organizations so that documents have good use value. Document management systems are sometimes only run at the parent institution centrally but are not implemented well at low management levels. This research is a development research with a development model design that is used as a reference in this research is the modified Borg and Gall development design. The research subject is the Satya Wacana Christian University undergraduate economic education study program. Data collection techniques using observation, interviews, expert judgment. The instrument used is an interview sheet, observation checklist. expert validation sheets and questionnaires. The results of this study indicate that the Education Database System created has the following feasibility test results: media experts get a rating of 4 in the "Good" category, practitioners get a 4.4 rating in the "Very Good" category, and from obtaining a 4.47 rating in the "Good" category. "Very Good" category. From several feasibility tests conducted, it was concluded that the database system from the media, practitioners, and users perspective was feasible to be applied. Trials in administrative activities show that the database system can assist administrative activities in the Economics Education S1 study program, so this database system is appropriate to be used as a system to assist administrative management in the study program. Through the database system developed, it is hoped that it can become an embryo for improving the administrative system, especially at the low management level. In further research, the database system can be developed according to the needs of other educational institutions.
\end{abstract}

Keywords: Database System; Tri Dharma College; Economic Education

\begin{abstract}
Abstrak: Pengelolaan dokumen merupakan hal yang penting bagi organisasi agar dokumen memiliki nilai guna yang baik. Sistem pengelolaan dokumen terkadang hanya dijalankan pada lembaga induk secara terpusat namun tidak terlaksana dengan baik pada level low management. Penelitian ini merupakan penelitian pengembangan dengan desain model pengembangan yang menjadi acuan dalam penelitian ini adalah desain pengembangan Borg and Gall yang telah dimodifikasi. Subjek penelitian yang diambil adalah program studi S1 pendidikan ekonomi Universitas Kristen Satya Wacana. Teknik pengumpulan data menggunakan observasi, wawancara, penilaian pakar. Instrumen yang digunakan adalah lembar wawancara, ceklish observasi. lembar validasi pakar dan angket. Hasil penelitian ini menunjukkan bahwa Sistem Database Pendidikan yang dibuat memiliki hasil uji kelayakan sebagai berikut ini: ahli media memperoleh penilaian 4 dalam kategori "Baik", praktisi memperoleh penilaian 4,4 dalam kategori "Sangat Baik", dan dari memperoleh penilaian 4,47 dalam kategori "Sangat Baik". Dari beberapa uji kelayakan yang dilakukan disimpulkan bahwa sistem database dari segi media, praktisi, dan pengguna layak untuk dapat diterapkan. Uji coba dalam kegiatan administrasi menunjukkan bahwa sistem database dapat membantu kegiatan administrasi pada program studi S1 Pendidikan Ekonomi, sehingga sistem database ini layak digunakan sebagai sistem untuk membantu pengelolaan administrasi pada program studi. Melalui sistem database yang dikembangkan ini diharapkan dapat menjadi embrio
\end{abstract}


untuk perbaikan sistem administrasi terkhusus pada level low management. Pada penelitian lanjutan sistem database dapat dikembangkan sesuai dengan kebutuhan lembaga pendidikan yang lain.

Kata kunci: Sistem Database; Tri Darma Perguruan Tinggi; Pendidikan Ekonomi

kemajuan zaman saat ini menjadikan teknologi informasi sebagai kebutuhan pokok bagi setiap bidang kehidupan, tanpa terkecuali bidang pendidikan. Lembaga pendidikan tentu saja memiliki sistem pendidikan yang sudah dikembangkan sedemikian rupa untuk dapat memfasilitasi kegiatan administrasi yang ada pada lingkungan kerjanya. Kehadiran sistem informasi pendidikan ini diharapkan dapat memberikan kemudahan bagi seluruh elemen pendidikan. Kehadiran sistem informasi juga diharapkan dapat mempermudah kegiatan audit ataupun kegiatan administratif yang lain yang membutuhkan data secara cepat dan akurat.

Belakangan ini, volume data dalam basis data meningkat secara geometris dengan area aplikasi yang luas di bidang komunikasi, kesehatan, pendidikan, keuangan, pertahanan, dan perkembangan internet (Folorunso \& Akinwale, 2010:25). Hal ini mendorong kehadiran sistem database dalam lingkup terkecil setiap organisasi. Terkhusus bidang pendidikan haruslah memiliki sistem database untuk menyimpan berbagai kegiatan akademik yang sudah dilakukan. Sebuah database berfungsi sebagai sumber informasi kolektif (Bin Maidin dkk., 2012:235). Database sebagai kumpulan data akan menjadi pusat informasi yang dapat diakses seacara mudah melalui sebuah sistem yang dikembangkan. Segala aktifitas akademisi mulai dari bidang pengajaran, siswa, kegiatan pendidikan memerlukan ruang untuk dapat didokumentasikan sebagai bukti eksistensi dari lembaga pendidikan.

Dermody \& Majekodunmi (2011:149) databse haruslah memiliki berbagai fitur yang dapat dimanfaatkan oleh pengguna. Pada konteks ini fitur standar yang harus ada seperti input data, penyimpanan data, rekapan penyimpanan atau fitur cetak pada rekap data. Selain itu keamanan dan kemudahan akses juga diperlukan dalam proses penggunaannya. Pada perkembangannya database pada umum juga sudah dapat diakses secara online, namun kehadiran database offline juga memiliki keunggulan tersendiri. Hal ini seperti jaminan keamanan data dan kemudahan akses.

Lembaga pendidikan pada umumnya sudah memiliki sistem pendidikan yang baik dan terintegrasi secara bertingkat. Univeritas memiliki sistem database Universitas yang diturunkan pada Fakultas. Demikian juga Sekolah tentu memiliki database secara nasional seperti pada tingkat Sekolah Dasar atau Sekolah Menengah. Sebagai pengguna di tingkat pertama terkadang memiliki kesulitan untuk mengakses data secara langsung. Misalnya pada kelompok Program Studi di Universitas atau kelompok Kompetensi Keahlian di Sekolah Menengah Kejuruan. Pada kondisi tertentu seperti audit intenal atau akreditasi kelompok ini haruslah memiliki data yang dibutuhkan secara cepat dan tepat dan sangat sulit untuk mendapatkannya.

Berdasarkan kondisi tersebut, dibutuhkan sistem database untuk dapat menyimpan dan mengelola data yang dibutuhkan. Database secara sederhana dapat dijelaskan sebagai data yang disimpan secara permanen di perangkat penyimpanan dan diambil kembali di memori oleh sistem informasi (Zygiaris, 2018:7). Database terus mengalami perkembangan dari waktu ke waktu. Berbagai inovasi juga mulai bermunculan mulai dari sistem database secara online, penyedia providen database gratis seperti google drive oleh google atau onedrive oleh microsoft. Database dapat dipandang sebagai cara yang sangat efektif untuk menyimpan dan menyusun data dari suatu sumber tertentu (Hamaz \& Benchikha, 2017:504). Sehingga setiap instansi atau lembaga pasti membutuhkan kehadiran database untuk dapat mendokumentasikan kebutuhan kegiatan mereka.

Dalam pembuatan sistem database diperlukan berbagai komponen pendukung. Feinberg (2017:336) struktur database dan sistem informasi dapat memberikan informasi yang berharga bagi setiap penguna. Selain komponen sistem informasi didalamnya juga harus dapat merefleksikan data agar dapat menjadi informasi yang dimanfaatkan oleh pengguna. Pengelolaan data yang fleksibel dapat menjadikan nilai 
tambah dalam segala kebutuhan dan pengambilan keputusan manajerial. Hal ini membuat databse harus dapat dikolaborasikan dengan sistem informasi. Simon (2015:9) sistem database yang baik akan membantu mengelola berbagai data secara terstruktur.

Perkembangan database elektronik telah menimbulkan banyak praktik dan kejadian yang menimbulkan ancaman serius terhadap privasi pribadi (Alotaibi, Clarke, \& Furnell, 2020). Pada poin yang utama sebuat sistem database haruslah memiliki keamanan akses yang baik. Hal ini bertujuan untuk menjaga keamanan data dari berbagai bentuk ancaman baik secara fisik, geografis, atau secara digital. Maraknya kegiatan pembajakan di era digital saat ini membuat pengembang sistem database harus berpikir ulang untuk dapat memberikan keamanan yang baik bagi setiap data yang dikelola.

Sistem manajemen database saat ini biasanya menerapkan mekanisme kontrol akses yang canggih untuk mencegah akses dan modifikasi yang tidak sah (Kieseberg, et al, 2013:53). Disinilah peranan admin menjadi sangatlah penting. Ayoku \& Okafor (2015:503) pengguna haruslah memiliki keterampilan teknologi informasi dalam mengelola databse. Pendidikan dan pelatihan khusus bagi pengguna haruslah dilakukan terlebih dahulu agar pengguna paham akan pentingnya keamanan dan kemudahan akses dalam penggunaan sistem database.

Selain itu user haruslah memiliki komitmen dan bertanggung jawab dalam melindungi privasi dari setiap data yang dikelola (Alotaibi, Clarke, \& Furnell, 2020). Selain keterampilan, sikap yang baik haruslah dimiliki oleh seorang admini atau user. Hal ini dimaksudkan selain sistem secara harafiah yang baik juga diimbangi dengan pengguna sistem yang bertanggung jawab. Sehingga sistem database akan dapat berjalan dengan baik sesuai dengan harapan.

Maula (2020:321) menambahkan karakteristik sistem database yang baik juga harus memperhatikan ketepatan waktu pengumpulan data, fasilitas TIK sesuai dengan kebutuhan, format pendataan, komitmen admin dan pengguna, sinkronisasi data dengan sistem database.

Hasil observasi dan wawancara yang dilakukan di Program Studi Pendidikan ekonomi, Universitas Kristen Satya Wacana menunjukan banyak data penting yang tidak termanajemen dengan baik, sistem informasi yang tersedia memiliki akses yang terbatas dan diperlukan personil khusus untuk bisa mengakses, banyak kegiatan akademis yang tidak terdokumentasikan dengan baik. Hal tersebut menimbulkan adanya kesulitan pada saat diadakannya kegiatan audit ataupun akreditasi, karena rekap data yang diperlukan haruslah di cari kembali secara bertahap.

Berdasarkan latar belakang tersebut, diperlukan pengembangan sistem database alternatif pemecahan permasalahan. Sistem yang dikembangkan haruslah disesuaikan dengan kebutuhan pengguna dan tetap memperhatikan aspek keamanan dan kemudahan akses. Dalam artikel ini dibahas tentang pengembangan database yang telah disesuaikan dengan kebutuhan objek penelitian. Jadi akan dimungkinkan untuk dilakukan penelitian lanjutan berdasarkan objek penelitian yang berbeda namun masih dalam substansi Database pendidikan.

\section{METODE}

Penelitian yang dilakukanmerupakanjenis penelitian dan pengembangan (researchand development). Model pengembangan yang menjadi acuan dalam penelitian ini adalah desain pengembangan Borg and Gall yang telah dimodifikasi. Adapun prosedur pengembangan yang dilakukan yang di lakukan yaitu analisis kebutuhan (research and information) perencanaan (planning), dan pengembangan produk (develop preliminary form of product). Untuk mengetahui kelayakan produk dilakukan uji kelayakan dari ahli media, dan praktisi. Untuk mengelola data angket diperlukan perubahan penilaian dalam bentuk kualitatif menjadi kuantitatif, yaitu dengan skala Likert. Untuk mengetahui kelayakan dari produk yang dikembangkan, hasil angket dari berbagai ahli di rata-rata dan dikategorikan dalam 5 kategori penilaian. Pada penilian $>4.2$ dalam kategori Sangat baik, > 3.4 - 4.2 adalah Baik, $>2.6$ - 3.4 adalah Cukup, $>1.8$ - 2.6 dalam kategori Kurang, dan $\leq 1.8$ dalam kategori Sangat kurang. Produk dinyatakan layak apabila memperoleh kalsifikasi baik dalam rata-rata skor. 


\section{HASIL DAN PEMBAHASAN}

\section{Analisis Kebutuhan (Research and information)}

Sanjaya (2015:138) survei lapangan dilakukan untuk menjaring berbagai fenomena yang terjadi dalam kehidupan nyata sehubungan dengan gagasan pengembangan produk yang ingin dihasilkan. Dalam penelitian ini survei lapangan dilakukan melalui dua teknik pengumpulan data yaitu observasi dan wawancara.

Observasi yang dilakukan dalam penelitian ini dilaksanakan dengan melakukan pengamatan serta pencatatan terhadap kegiatan manajerial terkait dengan pengelolaan data di Program Studi Pendidikan Ekonomi. Selain itu peneliti sebagai pelaku dari kegiatan manajerial diharapkan dapat mengetahui secara mendalam tentang informasi dari database yang akan dikembangkan. Hasil kegiatan observasi diketahui bahwa sebenarnya sudah ada sistem utama dalam pelaksanaan pengumpulan data akan tetapi untuk memperlancar kebutuhan data perlu dikembangkan sistem database yang mampu mengadaptasi kebutuhan program studi. Dan apabila dibutuhkan secara mendadak data dapat langsung tersedia. Selain kegiatan observasi juga dilakukan kegiatan wawancara kepada ketua program studi dan beberapa dosen. Diketahui bahwa secara periodik pasti akan ada kegiatan audit baik skala intenal maupun eksternal. Sehingga keseluruhan data yang dimiliki haruslah tertata dengan baik.

Survei literatur juga perlu dilakukan, diambil dari beberapa artikel dari jurnal internasional bereputasi untuk memperkuat penelitian. Berdasarkan analisa yang dilakukan diketahui beberapa data pendukung untuk pengembangan penelitian sebagi berikut: (1) sistem database harus memiliki sistem kontrol akses yang baik (Kieseberg, et al, 2013:53), (2) sistem database juga harus memiliki keamanan yang baik terhadap privasi pribadi (Alotaibi, Clarke, \& Furnell, 2020), (3) struktur database dan sistem informasi harus dapat memberikan informasi yang berharga bagi setiap penguna. (4) sistem database yang baik akan membantu mengelola berbagai data secara terstruktur (simon, 2015:9).

Selain studi literatur dilakukan juga analisis media untuk dapat mengetahui sumber daya yang dimiliki untuk mengembangkan sistem database. Diketahui dari hasil observasi komponen perangkat keras yang di miliki program studi sudah cukup memadai tersediannya komputer server yang terhubung dengan internet serta tersedia scanner untuk merubah data fisik menjadi softfile.

\section{Perencanaan (Planning)}

Perencaaan meliputi kegiatan penentuan lokasi dan sasaran pengembangan beserta agenda pengembangan yang dilakukan. Lokasi dan sasaran penelitian difokuskan pada Program Studi Pendidikan Ekonomi Universitas Kristen Satya Wacana. Beralamatkan di Jalan Diponegoro No.52-60, Salatiga, Kec. Sidorejo, Kota Salatiga, Jawa Tengah. Agenda pengembangan meliputi tahap persiapan meliputi pengajuan judul dan izin penelitian. Tahap analisis kebutuhan pengembangan mencakup analisis pengguna, analisis media, analisis sarana dan prasarana. Dilanjutkan tahap desain pembuatan produk yang dilanjutkan dengan validasi ahli.

\section{Pengembangan Produk (Develop preliminary form of product)}

Pengembangan produk yang dilakukan terdiri dari beberapa tahapan yaitu Pra Produksi, Produksi, dan Pasca Produksi. Tahapan Pra Produksi dimulai dengan penentuan topik data untuk dibuat dalam sistem database. Pada proses inin melibatkan ketua program studi dan staff tata usaha unuk menentukan kajian data yang tepat untuk dibuatkan sebuah sistem informasi. Kesimpulan akhirnya adalah database yang akan dibuat akan berorientasi pada Tridarma Perguruan Tinggi yang menjadi kegiatan rutin dosen yaitu pengajaran, penelitian dan pengabdian masyarakat, ditambahkan data penunjang lain. Staff tata usaha menekankan agar database dibuat secara offline demi menjaga keamanan data. Mengingat data yang dibapai juga meliputi data pribadi dosen sekaligus data yang bersifat rahasia bagi fakultas. Kemudian dilakukan pemilihan dan pengumpulan bahan, pengembang sekaligus peneliti mencari software yang tepat untuk dilakukan pengembangan yang disesuaikan perangkat hardware yang ada. Sistem dikembangkan melalui software Microsoft Access yang nanti akan dimasukan dalam komputer server. 
Feinberg (2017:336) untuk dapat memfasilitasi kegiatan membaca database, penelitian harus mengembangkan alat yang memfokuskan perhatian pengguna pada penerapan struktur database ke konten database. Berdasarkan haltersebut dilakukan tahapan selanjutnya adalah dilakukan Desain Garis Besar Isi Media (GBIM). GBIM merupakan petunjuk yang dijadikan pedoman dalam menulis naskah. GBIM dibuat dilakukan pada tahap analisis kebutuhan. GBIM didalamnya terdapat pokok-pokok media yang akan dimasukkan dalam mini sistem database yang akan dibuat. Dimulai dari isian data dosen, data pengajaran, data penelitian, data pengabdian masyarakat, serta data pendukung lainnya. Tahapan akhir dari tahapan Pra Produksi dalah membuat Storyboard. Pengembang membuat storyboard sebagai rancangan secara umum berbentuk gambaran Sistem Operasional Prosedur (SOP).

Adapun gambarannya sebagai berikut:

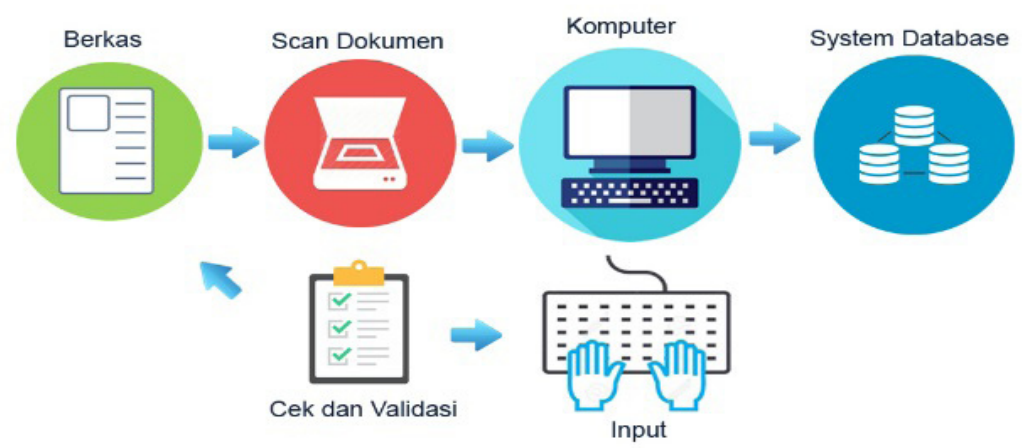

Gambar 1 Storyboard Sistem Database yang dikembangkan

Gambar 1 menjelaskan pengembangan sistem database dimulai dari pengumpulan informasi yang dicek dan disetai bukti fisik, data diinput melalui sistem informasi yang telah dikembangkan sedangkan bukti fisik di scan agar dapat berubah menjadi softfile. Kemudian bukti fisik di kembalikan. Data dan bukti fisik yang sudah berupa softfile kemudian diinput dalam sistem database yang dikembangnkan. Dengan catatan dapat diakses secara mudah. Proses pengembangan media tersebut meningkat ke tahap selanjutnya yaitu tahap development (pembuatan produk).

Dalam tahap produksi yaitu proses mengubah naskah dan storyboard menjadi sebuah media yang dapat menyimpan data. Adapun beberapa program yang dibutuhkan yaitu Microsoft Access sebagai basis software pembuatan sistem database, Adobe Photoshop dan Corel Draw sebagai editing ikon gambar, Microsoft Excel untuk mengekstrak rekap data dari sistem database. Berikut beberapa gambaran dari sistem yang dikembangkan:

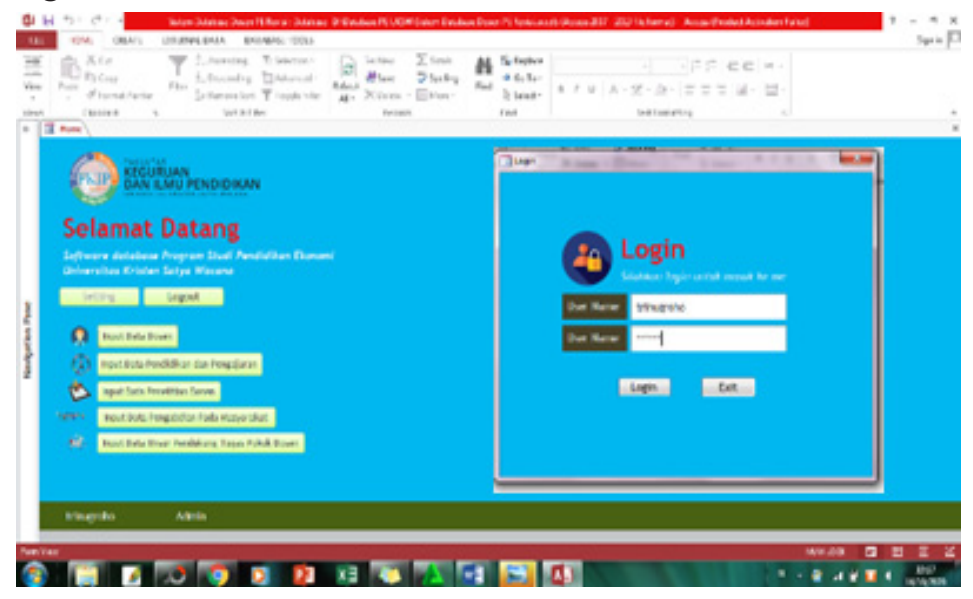

Gambar 2 Tampilan Log in dan halaman Home

Gambar 2 menunjukan tampilan awal dari database yang dikembangan, log in berkaitan dengan akses sistem yang sudah diseting sesuai dengan username dan password pengguna atau admin yang 
di tunjuk untuk mengelola sistem. Setelah sukses melakukan login sistem akan merujuk pada halaman awal dimana menu untuk mengisi form Tri Darma Perguruan Tinggi tersedia.

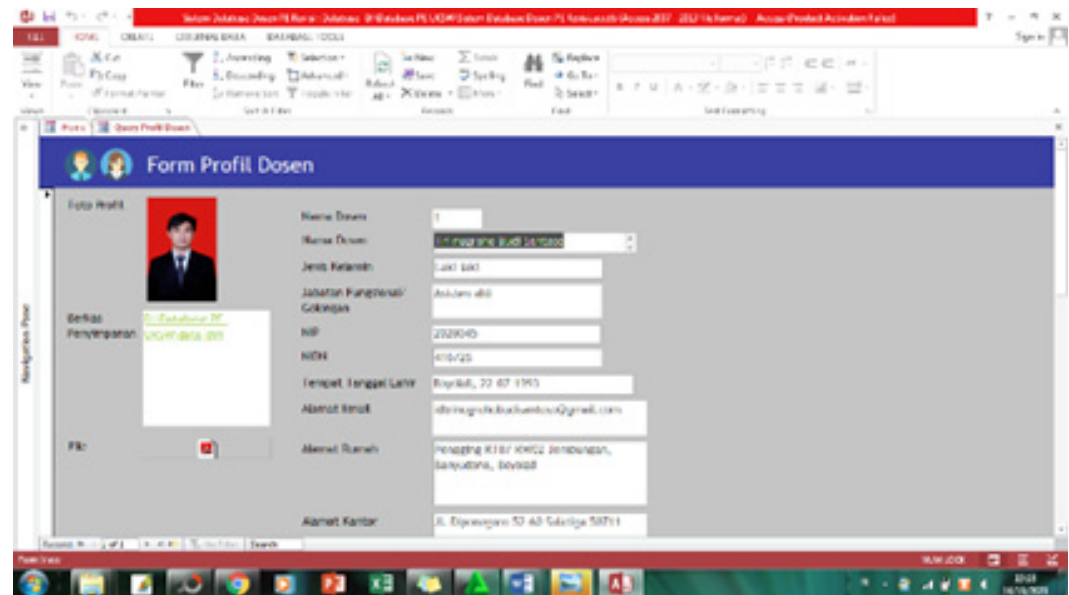

Gambar 3 Tampilan form profil dosen

Gambar diatas merupakan form untuk mengisi data awal dosen yang berisikan informasi pribadi dan bebagai status capaian dosen yang sudah dimiliki. Jika sudah disimpan maka data akan otomatis terrekap dalam rekapan profil dosen.

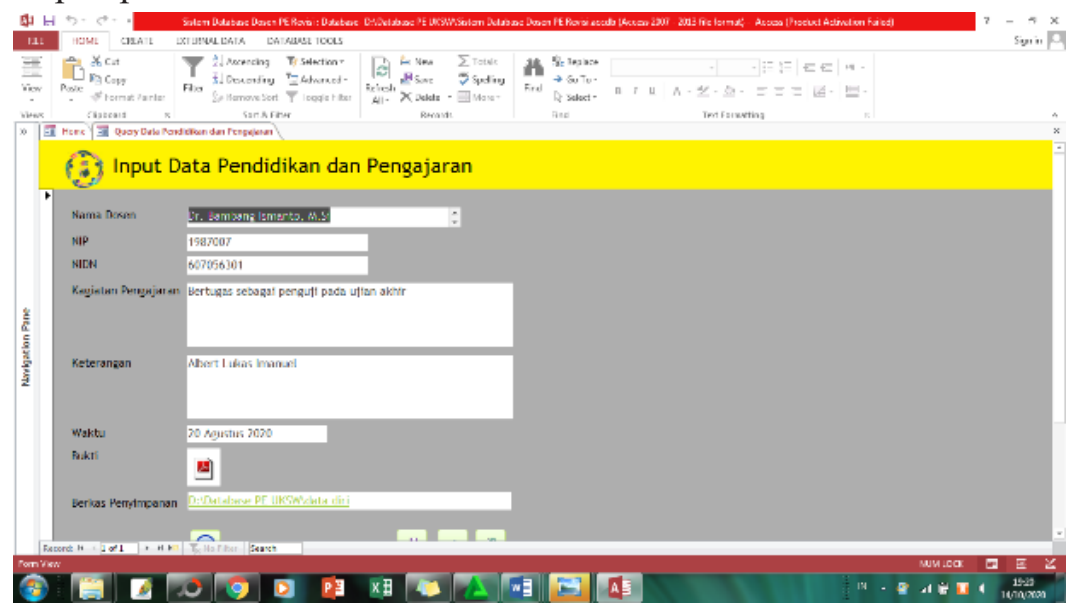

Gambar 4 Tampilan Form Data Pendidikan dan Pengajaran

Gambar 4 adalah form data untuk pendidikan dan pengajaran dapat diisi kegiatan pendidikan dan pengajaran yang dilakukan misalnya: melaksanakan perkuliahan dan pembimbingan sampai melaksanakan kegiatan pengembangan diri untuk meningkatkan kompetensi. Jika sudah disimpan maka data akan otomatis terrekap dalam rekapan data pendidikan dan pengajaran.

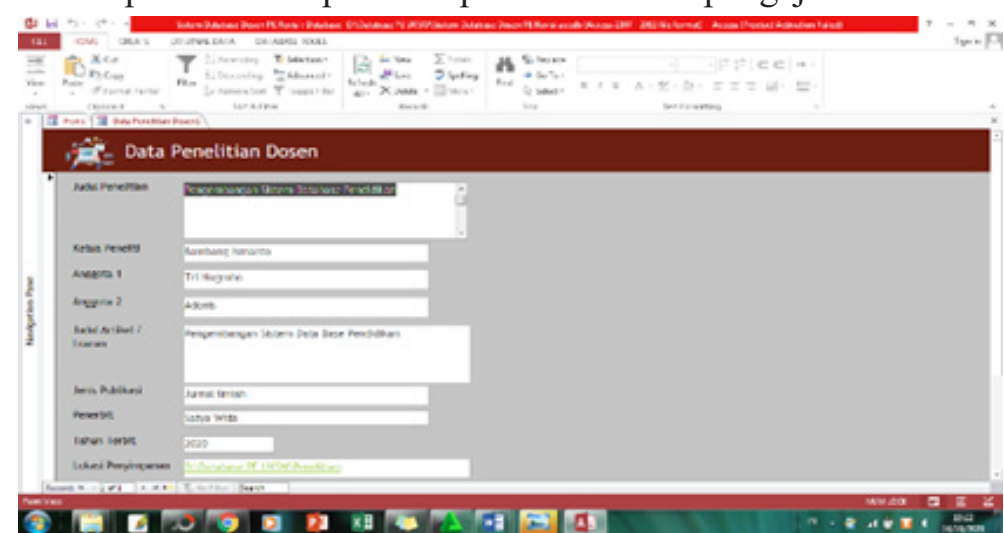

Gambar 5 Tampilan Form Data Penelitian Dosen 
Gamber 5 menjelaskan isian form pada penelitian dosen dapat diisi kegiatan penelitian yang dilakukan misalnya: menghasilkan karya ilmiah sampai membuat rancangan dan karya. Jika sudah disimpan maka data akan otomatis terrekap dalam rekapan data penelitian dosen.

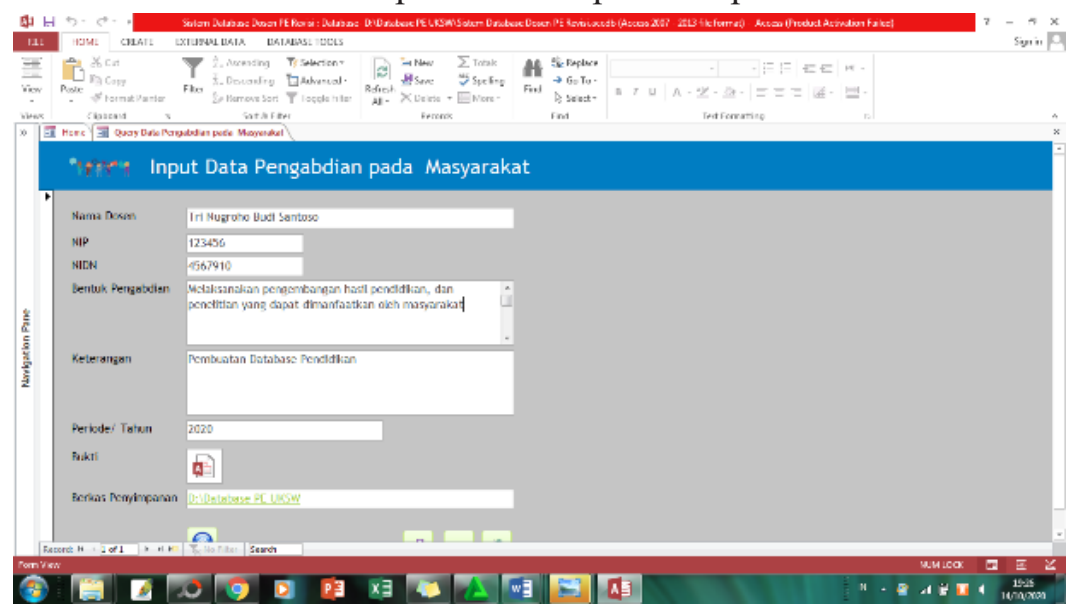

Gambar 6 Tampilan Form Data Pengabdian pada Masyarakat

Gambar 6 merupakan form data pengabdian masyarakat dapat diisi kegiatan pengabdian pada masyarakat yang dilakukan misalnya: menduduki jabatan pimpinan pada suatu lembaga sampai pada membuat karya pengabdian pada masyarakat. Jika sudah disimpan maka data akan otomatis terrekap dalam rekapan data pengabdian pada masyarakat.

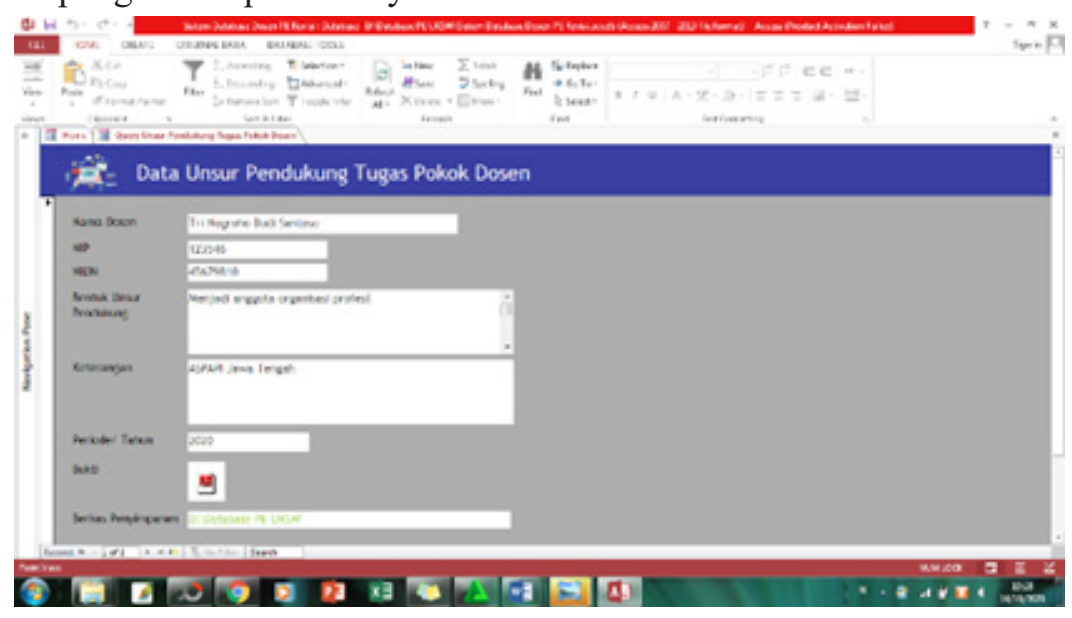

Gambar 7 Tampilan Form Data Unsur Pendukung Tugas Pokok

Gambar 7 menjelaskan form untuk data unsur pendukung tugas pokok dapat diisi misalnya: menjadi anggota dalam suatu Panitia sampai dengan prestasi dibidang olahraga/humaniora.

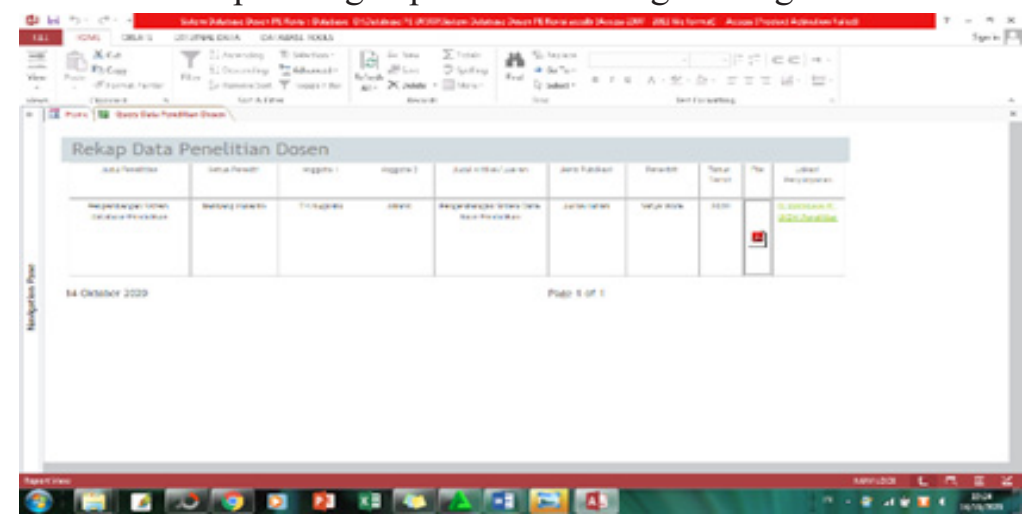

Gambar 8 Tampilan Rekap Data 
Gambar 8 mengambarkan tampilan pada rekap data, disetiap form memiliki rekapdata yang dapat di ekstrak dalam format pdf atau xls untuk mempermudah pengolahan data. Pada tahapan yang terakhir adalah tahapan Pasca Produksi merupakan tahap yang menyatakan bahwa media sistem database telah selesai dibuat, dan melalui berbagai tahapan pada proses produksi. Meski demikian media masih perlu dilakukan uji kelayakan untuk memastikan kualitas sebelum sistem sebelum di pakai atau disebarkan. Selanjutnya dilakukan konsultasi dengan ahli media, praktisi, dan pengguna yang telah ditentukan sebelumnya. Dengan harapan memperoleh kritik dan masukan untuk kemajuan media. Jika sudah memperoleh masukan dilakukan revisi dan penyempurnaan produk.

\section{Uji Kelayakan}

Sistem yang dikembangkan mendukung kolaborasi antar profesional dalam tahap desain (Masior, 2019:80). Berdasarkan hal tersebut dilakukan uji kelayakan dengan menggunakan analisis statistik deskriptif digunakan untuk menganalisis dan mendeskripsikan data yang telah diperoleh. Hasil dari analisis statistik deskriptif digunakan untuk mengetahui kelayakan dari produk yang dikembangkan dalam penelitian ini.

Berdasarkan pertimbangan dan kesesuaian bidang, validasi sistem informasi pada penelitian ini adalah Dwi Kristiani, S.Kom, M.Cs sebagai dosen di bidang Sistem Informatika.

Tabel 1 Uji Kelayakan oleh Ahli Sistem Informasi

\begin{tabular}{lll}
\hline No & Kriteria & Nilai \\
\hline 1 & Konsep penyusunan sistem database & 5 \\
2 & Struktur Sistem database & 4 \\
3 & Komponen pendukung & 3 \\
4 & Keamanan & 5 \\
5 & Fitur pembaharuan & 3 \\
\hline & Rata-rata & 4
\end{tabular}

Berdasarkan Tabel 1 diketahui rata-rata keseluruhan adalah 4 yang berarti dapat dikatakan juga bahwa secara teoritis media yang digunakan dalam pengembangan Sistem database pendidikan dalam kategori "Baik". Hal ini sesuai dengan hasil penelitian yang dilakukan Sundari dan Musril (2020) menjelaskan bahwa pengujian validitas dan praktikalitas sistem Sistem Informasi Database Alumni dapat menunjukan kelayakan sistem yang digunakan.

Validasi media pada penelitian pengembangan ini adalah Mustofa Asfi Hani, S.Sn sebagai pendidik sekaligus praktisi pada bidang multimedia sekaligus pemilik usaha 2R Industry'Art dan bekerja sebagai guru pada kompetensi keahlian multimedia selama 10 tahun.

Tabel 2. Uji Kelayakan oleh Ahli media

\begin{tabular}{lll}
\hline No & Kriteria & Nilai \\
\hline 1 & Akses kedalam sistem & 5 \\
2 & Desain tampilan & 5 \\
3 & Fitur software & 4 \\
4 & Pemahaman fitur yang digunakan & 3 \\
5 & Fleksibilitas sistem & 5 \\
\hline & Rata-rata & 4,4 \\
\hline
\end{tabular}

Berdasarkan Tabel 2 diketahui rata-rata keseluruhan adalah 4,4 yang berarti dapat dikatakan juga bahwa dari segi penggunaan berbagai macam fasilitas dari Sistem database pendidikan dalam kategori "Sangat Baik". Hal ini sesuai dengan hasil penelitian yang dilakukan Yuneti dkk., (2020) konten, keterbacaan, kecanggihan teknologi, dan akses yang layak digunakan dalam pengembangan database kinerja dosen berbasis android dapat menunjukan kelayakan media yang dikembangkan.

Validasi pengguna pada penelitian pengembangan ini adalah dosen Program Studi Pendidikan 
Ekonomi Universitas Kristen Satya Wacana yang nantinya sebagai user dalam penggunan Sistem Database.

Tabel 3 Uji Kelayakan oleh Pengguna

\begin{tabular}{|c|c|c|c|c|c|}
\hline \multirow{2}{*}{ No } & \multirow{2}{*}{ Kriteria } & \multicolumn{3}{|c|}{ Responden } & \multirow{2}{*}{ Total } \\
\hline & & I & II & III & \\
\hline 1 & Penggunaan & 5 & 4 & 4 & 4,33 \\
\hline 2 & Kesesuaian dengan kebutuhan & 4 & 5 & 4 & 4,33 \\
\hline 3 & Pengelolaan data & 5 & 4 & 5 & 4,67 \\
\hline 4 & Akses data & 3 & 4 & 5 & 4,00 \\
\hline 5 & Output yang diharapkan & 4 & 4 & 5 & 4,33 \\
\hline & Rata-rata & 4,2 & 4,2 & 4,6 & 4,33 \\
\hline
\end{tabular}

Berdasarkan Tabel 3 diketahui rata-rata keseluruhan adalah 4,33 yang berarti dapat dikatakan juga bahwa konten penggunaan media ebook dalam kategori "Sangat Baik" berarti dapat dikatakan juga bahwa dari segi penggunaan di lapangan, Sistem database pendidikan dalam kategori "Sangat Baik". Hal ini sejalan dengan riset yang dilakukan Faslah (2015) yang menjelaskan dengan respon pengguna dalam uji kelayakan sistem database yang digunakan menunjukan bahwa database yang dikembangkan layak untuk digunakan.

\section{SIMPULAN DAN SARAN}

\section{Simpulan}

Kehadiran sebuah sistem pendidikan tentu saja sudah menjadi hal pokok pada lembaga pendidikan saat ini. Namun pada level kepemimpinan tertentu dimana data primer di temukan tekadang pengelolaan data masih dirasa kurang maksimal. pengembangan database ini dimaksudkan untuk mengatasi hal tersebut. Selain ketersediaan sistem pendidikan yang terpusat sisttem data base yang dikembangkan ini dimaksuktan setidaknya dapat menjadi terminal sistem untuk dapat menjebatani pengelolaan data di tingkat manajerial bawah kepada pengelolaa sistem informasi di tingkat manajerial atas.

Software pengembangan didesain secara offline untuk memprioritaskan tingkat keamanan data. Dengan software Microsoft Office memiliki keuntungan adaptasi yang baik di berbagai tempat karena software microsoft merupakan standar minimum dari kepemilikan perangkat komputer. Sistem database yang dikembangkan diadaptasikan untuk mengelola kebutuhan manajerial level bawah pada lembaga perguruan tinggi dan difokuskan untuk dapat mengelola data terkait dengan Tri Darma Perguruan Tinggi yang meliputi pengajaran, penelitian dan pengabdian kepada masyarakat. Setelah selesai di produksi sistem yang telah dibuat dilakuka uji kelayakan sebelum dapat dipakai di lapangan.

Hasil uji kelayakan yang dilakukan disimpulkan bahwa Sistem database dari segi media, praktisi, dan pengguna sangat layak untuk dapat diterapkan. Penelitian pengembangan ini masih dapat dikembangkan lagi dalam ruang lingkup yang lebih luas. Karakteristik software yang bersifat terbuka dan sangat fleksibel dapat disesuaikan dengan objek penelitian yang lain dalam bidang pendidikan.

\section{Saran}

Dengan menyesuaikan data yang digunakan sesuai dengan kondisi objek dilapangan. Bidang pendidikan pada tingkat Sekolah Menengan Kejuruan merupakan salah satu objek yang direkomendasikan untuk pengembangan berikutnya. Hal ini disebabkan adanya level manajerial mulai dari Kepala Sekolah, Wakil Kepala Sekolah dan bidang yang digeluti serta kompetensi keahlian sebagai target yang tepat untuk pengembangan sistem ini. 


\section{DAFTAR RUJUKAN}

Alotaibi, F. G., Clarke, N., \& Furnell, S. M. (2020). A novel approach for improving information security management and awareness for home environments. Information \& Computer Security.

Ayoku, O. A., \& Okafor, V. N. (2015). ICT skills acquisition and competencies of librarians. The Electronic Library, 33(3), 502-523.

Bin Maidin, S., Campbell, I., \& Pei, E. (2012). Development of a design feature database to support design for additive manufacturing. Assembly Automation, 32(3), 235-244.

Dermody, K., \& Majekodunmi, N. (2011). Online databases and the research experience for university students with print disabilities. Library Hi Tech, 29(1), 149-160.

Faslah, R. (2015). Pengembangan Pembelajaran Manajemen Database Berbasis Web CMS JOOMLA Pada Mahasiswa Pendidikan Administrasi Perkantoran Fakultas Ekonomi Universitas Negeri Jakarta. Jurnal Ilmiah Econosains, 13(1), 73-87.

Feinberg, M. (2017). Reading databases: slow information interactions beyond the retrieval paradigm. Journal of Documentation, 73(2), 336-356.

Folorunso, O., \& Akinwale, A. (2010). Developing visualization support sistem for teaching/learning database normalization. Campus-Wide Information Sistems, 27(1), 25-39.

Hamaz, K., \& Benchikha, F. (2017). A novel method for providing relational databases with rich semantics and natural language processing. Journal of Enterprise Information Management, 30(3), 503-525.

Kieseberg, P., Schrittwieser, S., Morgan, L., Mulazzani, M., Huber, M., \& Weippl, E. (2013). Using the structure of $\mathrm{B}+$-trees for enhancing logging mechanisms of databases. International Journal of Web Information Sistems, 9(1), 53-68.

Masior, J. (2019). Design requirements on the integration of technology databases. Measuring Business Excellence. 23(1), 80-90.

Maula, L. H. (2020). Analisis Kesulitan Pengelola Lembaga Pendidikan Dalam Pelaksanaan EMIS. Jurnal Elementaria Edukasia, 3(2), 321-328.

Simon, J. C. (2015). Building your own ERMS. Library Hi Tech News, 32(3), 9-12.

Sundari, R. A. (2020). Pengembangan Sistem Informasi Database Alumni (Studi Kasus: SMAN 1 2x11 Enam Lingkung). Jurnal Telematika, 15(2), 115-124.

Yuneti, A., Hamdan, H., Pestalozi, D., Putra, M. R., \& Erwandi, R. (2020). Pengembangan Database Evaluasi Kinerja Dosen Berbasis Android di STKIP PGRI Lubuklinggau. Journal Of Administration and Educational Management (ALIGNMENT), 3(1), 11-19.

Zygiaris, S. (2018). The DataBase Environment. Database Management Sistems, 3-20. 